\title{
Extensive Performance Evaluation of Dual Booster Mirror Solar Cooker under Tracking Free Conditions
}

\author{
Muhammd $\operatorname{Irfan}^{1}$, Suhail Zaki Farooqui ${ }^{2}$, Asadullah khan ${ }^{3}$ \\ ${ }^{1,2,3}$ Department of Renewable Energy Engineering, U.S.-Pakistan Center for Advance Studies in Energy, University of \\ Engineering and Technology Peshawar, Pakistan \\ irfankhan9732@gmail.com ${ }^{1}$, suhail.zaki@uetpeshawar.edu.pk ${ }^{2}$, asadullah8080@gmail.com ${ }^{3}$ \\ Received: 05 October, Revised:10 November, Accepted: 06 December
}

\begin{tabular}{|ll}
\hline Abbreviations and Acronyms \\
SBC & Solar Box Cooker \\
DBM & Dual Booster Mirrors \\
BM & Booster Mirror \\
FOM & Figure Of Merit \\
FFOM & First Figure Of Merit \\
SFOM & Second Figure OF Merit \\
$\alpha$ & Solar altitude Angle \\
6 & Solar Declination Angle \\
$\omega$ & Hour Angle \\
$\varphi$ & Latitude of the location \\
$\mathrm{t}_{\mathrm{s}}$ & Solar Time \\
SR & Solar Radiation \\
OTA & Optimal Tilt Angle
\end{tabular}

Abstract-The aim of this research work is to conduct an extensive performance evaluation of a box type dual Booster Mirror solar cooker under tracking free conditions. To cope up with the need for continuous adjustment of the cooker during the cooking operation the optimal tilt angles of the Booster Mirrors have been calculated through numerical calculations for the location of $34^{0}$ latitude. To evaluate the Performance parameters of the cooker, tests under tracking free conditions have been carried out and parameters such as, First and Second Figure of Merit, Cooking power, exergy efficiency and the Quality Factor, are evaluated for the BSC. Moreover, the cooker is tested onfield and different types of food items are cooked. The results indicate that orienting the Booster Mirrors at their respective optimal angles provides a viable and convenient alternative to the need for continuous tracking of the sun during cooking hours. With this technique the said cooker can be used for cooking $6.4 \mathrm{~kg}$ of 6 different dishes in a single day i-e. from 9:00 Am to 3:00 Pm in two batches.
Keywords - Optimal tilt angles, Box Type Solar Cooker, Tracking free conditions

\section{INTRODUCTION}

Cooking counts as one of the major fuel consuming activity in the world. Conventional cooking poses a major threat to the forests since, approximately two-third of the developing country's population depends on firewood for their daily cooking and heating needs [1]. Solar cooking is a renewable activity that utilizes solar radiation to cook food. Solar cooking is a cost free, environment friendly, and convenient replacement for conventional cooking practices. Among all the types of solar cookers, box type solar cookers are the most preferred ones because of their lower cost and simple design. SBC utilizes the greenhouse effect to cook the food. Typically, a SBC has two transparent plan mirrors that act as the lid of the cooker box. Food is placed in the cooker box and the lid is closed under airtight conditions. The temperature of the air inside the cooker box is increased because of the greenohouse effect and thus the food inside the box starts cooking. The two BMs having the same size as the aperture of the SBC are mounted on both the edges of the SBC. These BMs direct the solar radiation onto the aperture of the SBC, thus making extra radiation fall on the aperture and thus speeding up the cooking process. The main disadvantage in SBC is the need for adjustment after every 1530 minutes during the cooking operation due to change in the solar azimuth angle. The need for the solar tracking, makes the cooking process more hectic especially when the cooker is loaded, and is a major hurdle in the mass adoption of the SBC for cooking purposes [2]. 


\section{A. The Dual Booster Mirror Solar Cooker}

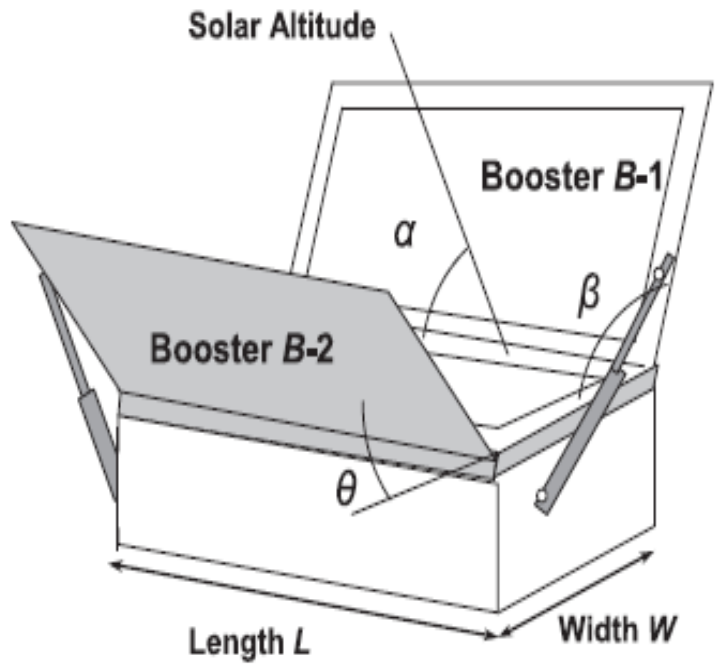

Figure. 1 The DBM solar cooker with length $\mathrm{L}$ and width $\mathrm{W}$ and the BMs inclined at their respective angles with the horizon., $\alpha$ reprsent altiitude angle

The DBM Solar Cooker has two booster mirrors attached to the edges of the cooker box. The direct solar radiation fall on the aperture of the cooker directly where as the diffused radiation are reflected by the BMs onto the aperture of the cooker. The dimensions of the BMs are the same as that of the solar cooker's base. The BM B-1 and B-2 are inclined at an angle of $\beta$ and $\theta$ with the horizon respectively as shown in Fig.1.

In order to make more and more diffused solar radiation fall on the solar cooker, The inclination of both the BMs should be varied every 15-30 minutes. To make the cooking process free of the need for solar tracking the optimal tilt angles of both the BMs are found through numerical calculations. This section covers the analysis of the solar radiation harnessed by both the BMs for 3 hours before and 3 hours after the solar noon I-e from 9:00 am to 3:00 pm, which is considered to be the most optimal time for solar cooking. The solar altitude angle at an instant is given by

$\alpha=\sin ^{-1}[\sin \delta \sin \emptyset+\cos \sigma \cos \omega \cos \varphi]$ degrees

Where as the hour angle $\omega$ is shown by

$\omega=15\left(t_{s}-12\right)$ degrees

The solar declination angle is given by

$\delta=\sin ^{-1}[0.39795 \cos [.98563(N-173)]$ degrees

The value of $\mathrm{N}$ in equation (3) varies form 1-365 based on the number of the day of the year. As fig.2. shows, the BMs B-1 and $\mathrm{B}-2$ are inclined at angle $\beta$ and $\theta$ respectively with the horizon.W is the width of the BMs. As the Fig.2 shows, I is the solar radiation intensity on a horizontal surface at time $t$ then the solar radiation intensity on a surface held normal to the Sun $I^{\prime}$ will given by

$$
I^{\prime}=\frac{I}{\sin \alpha}
$$

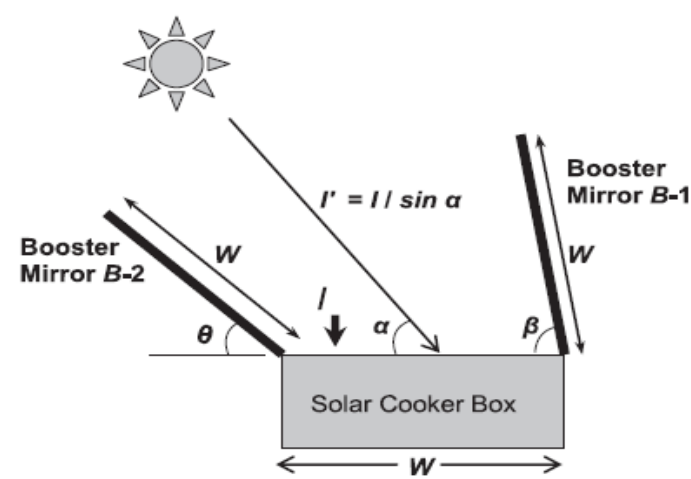

Figure. 2 The Booster Mirrors inclined at their respective angles. W represents the width of the BMs

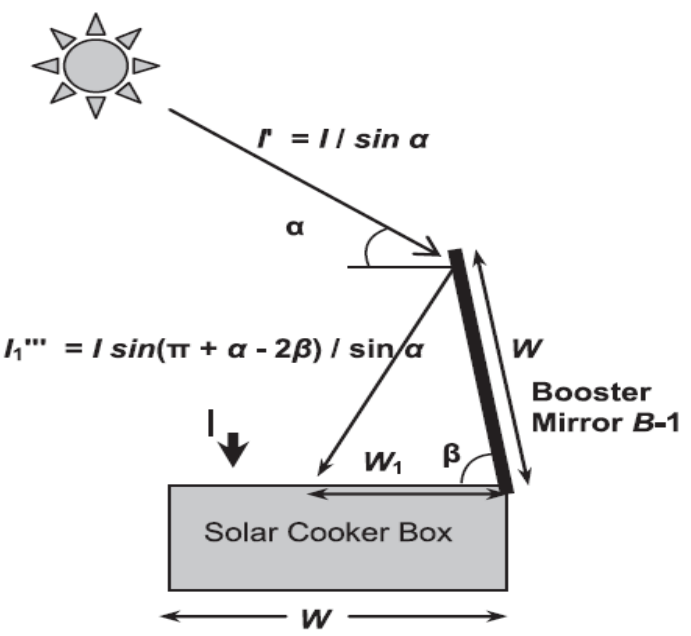

Figure.3 Solar radiation intensity on the top glazing after being reflected by the BM B-1

The solar radiation intensity normal to the surface of B-1 which is represented by $I_{1}^{\prime \prime}$ as shown in fig.3. is given by

$$
I_{1}^{\prime \prime}=I^{\prime} \sin (\pi+\alpha-\beta)
$$

If ' $\mathrm{W}$ ' represents the width of the solar cooker and $\mathrm{W}_{1}$ represent the projection length of the reflected light on the horizontal surface then the solar irradiance attenuated by the horizontal surface equals to the power per unit length reflected by the mirror. This statement is given by

$$
I_{1}^{\prime \prime \prime} W_{1}=I_{1}^{\prime \prime} W
$$

$I_{1}^{\prime \prime \prime}$ represents the solar irradiance reflected by the B-1 onto the top surface of the cooker. As clear the incident radiation is making an angle $(\beta-\alpha)$ with the mirror, this implies that the angle made by the reflected radiation with the horizontal surface of the top glazing will be $(\pi+\alpha-2 \beta)$. Thus by the law of sines

$$
\frac{W}{\sin (\pi+\alpha-2 \beta)}=\frac{W_{1}}{\sin (\pi+\alpha-2 \beta)}
$$

By comparing equation 7 and 8 we get

$$
I_{1}^{\prime \prime \prime}=I \cdot \sin (\pi+\alpha-2 \beta) / \sin \alpha
$$


If the same analysis is carried out for BM B-2 it will give the results as

$$
\begin{aligned}
& I_{2}^{\prime \prime}=I^{\prime} \sin (\alpha-\theta) \\
& I_{2}^{\prime \prime \prime}=\frac{I_{2}^{\prime \prime} \sin (2 \theta-\alpha)}{\sin (\alpha-\theta)}=\frac{I \sin (2 \theta-\alpha)}{\sin \alpha} \\
& W_{2}=\frac{W \sin (\alpha-\theta)}{\sin (2 \theta-\alpha)}
\end{aligned}
$$

Integrating $\left(I . W+I_{1}^{\prime \prime \prime} \cdot W_{1}+I_{2}^{\prime \prime \prime} \cdot W_{2}\right)$ for 9:00 Am to 12:00 Pm for the ramge of values of $\alpha$ between $\alpha_{\min }$ i-e at 9:00 Am and $\alpha_{\max }$ i-e at 12:00 Pm for the fixed values of $\theta$ and $\beta$, gives the total energy per unit length received by the solar cooker box. The values of $W_{1}$ and $W_{2}$ are calculated using equation (9) and (12). Thus the total solar energy attained by the SBC is gives as

$E=\int_{t_{1}}^{t_{2}}\left(I \cdot W+I_{1}^{\prime \prime \prime} \cdot W_{1}+I_{2}^{\prime \prime \prime} \cdot W_{2}\right) d t$ joules

\section{B. Calculation of the Optimal tilt Angles for Booster Mirrors}

The optimal tilt angles of the BMs are the angles at which, if the BMs are tilted, will give the maximum energy output for a specific day of the year. Since the extra terrestrial radiation intensity $I_{0}$ on a surface held normal to the sun on a specific day of the year is given as

$$
\begin{aligned}
& I_{o}= I_{S C}\left[1+0.034412 \cos \left\{\frac{2 \pi(N-3)}{365.35}\right\}\right. \\
& I_{S C} ; 1367 \mathrm{~W} / \mathrm{m}^{2} \\
& \mathrm{~N} ; \text { Day of the year }
\end{aligned}
$$

The extra terrestrial solar radiation on a horizontal surface $I_{o h}$ is given as

$I_{o h}=I_{o} \operatorname{Cos} \theta_{z}$

$\theta_{z} ;$ Zenith Angle

$\theta_{z}$, In terms of the solar altitude angle $\alpha$ is given as

$\theta_{z}=90-\alpha$

The extra terrestrial solar radiation when reach the earth atmosphere is reduced to

$$
I=I_{o h} \cdot 0.7^{A M \cdot 678}
$$

The Air Mass A.M is given as

$$
A \cdot M=\left[\cos \theta_{z}+0.50572\left(96.07995-\theta_{z}\right)^{-1.6364}\right]^{-1}
$$

Using the SR intensities, as deduced by the equations

(14)-(18) and (8)-(12), for a given location i.e. Latitude Angle, the last two components of Eq.(13) may be integrated between the minimum and maximum value of altitude angle i.e. the altitude angle at 9:00 am and at 12:00 PM respectively for specific value of $\theta$ and $\beta$ to calculate the total energy contributed by each of the two BMs. The most optimal values of $\theta$ and $\beta$ are achieved by repeating the integration for all possible values of $\theta$ between $0^{\circ}$ and $60^{\circ}$ and for the value of $\beta$ between $40^{\circ}$ and $110^{\circ}$ for which the total energy received by the cooker is maximum[2].

\section{B. Experimental Results}

The fore-mentioned calculations are carried out for location of $34^{\circ}$ Latitude i-e Peshawar Pakistan for the DBM solar cooker and the values of the OTAs for a $34^{\circ}$ Latitude location, if plotted against the days of the year will give the result as shown in Fig.4. The BMs B-1 and B-2, with a length of $1.0 \mathrm{~m}$ and width $0.5 \mathrm{~m}$ if inclined at their calculated optimal tilt angles will contribute to the energy gained by the cooker as shown in Fig.5. Fig.6 is the depiction of energy contributed to the BSC by both the BMs and the top glazing. Fig.7 shows the dual BM Solar cooker with its primary Booster Mirror B-1 facing South.The dimensions of the SBC used for the evaluation of the dual BM solar cooker are given in Table.1. The optimal values of the tilt angles for both the booster mirrors calculated through numerical calculations for the location of $34^{\circ}$ Latitude are given in Table. 1 and Table. 2

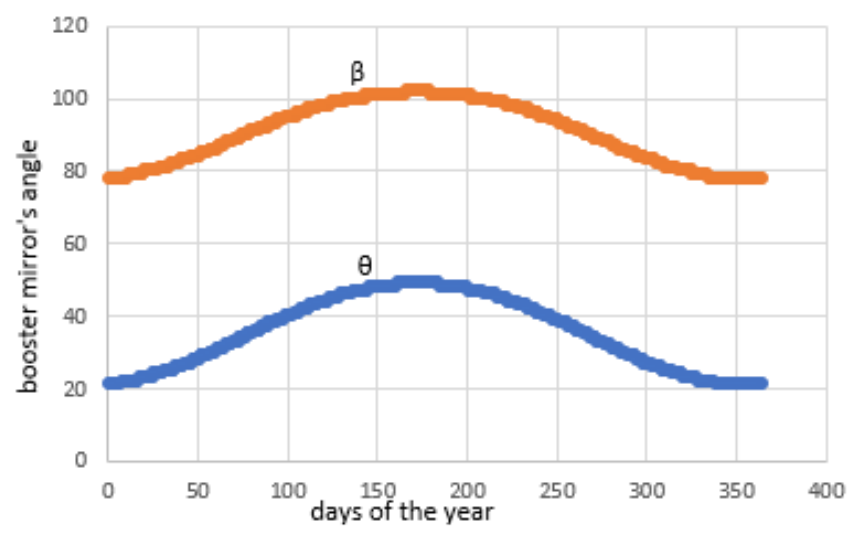

Figure.4 Plot of the optimal tilt angles of BMs Vs days of the year

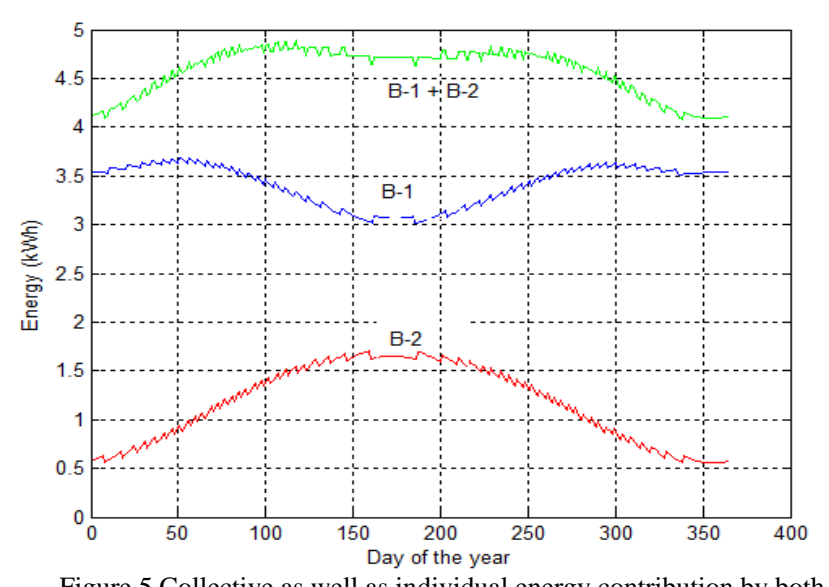

Figure.5 Collective as well as individual energy contribution by both BMs to the SBC 


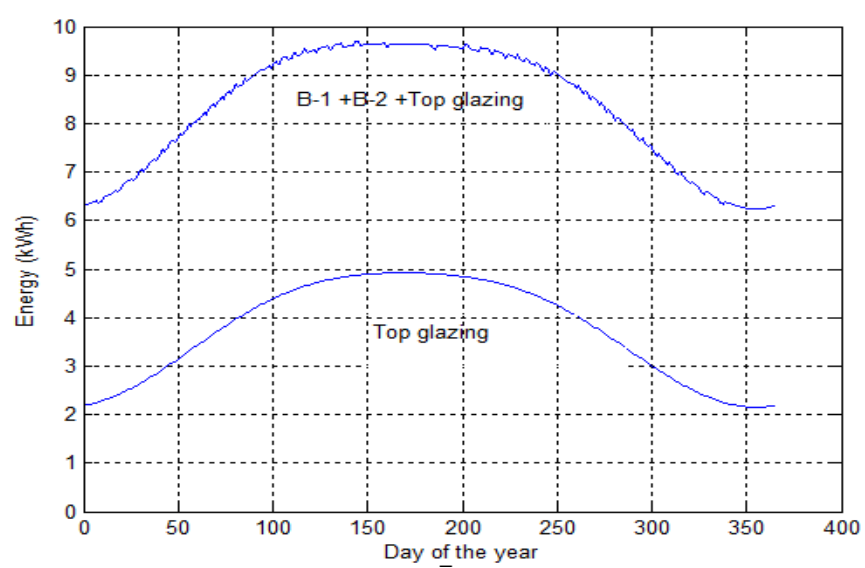

Figure.6 energy contributed by both the booster mirrors and top glazing

TABLE. 1 OPTIMAL TILT ANGLES OF THE BOOSTER MirROR B-1 AND THEIR CORRESPONDING DAYS FOR $34^{0}$ LATTUDE LOCATION

\begin{tabular}{cccccccccccc}
\hline $\mathrm{N}$ & $\beta_{\text {opt }}$ & $\mathrm{N}$ & $\beta_{\text {opt }}$ & $\mathrm{N}$ & $\beta_{\text {opt }}$ & $\mathrm{N}$ & $\beta_{\text {opt }}$ & $\mathrm{N}$ & $\beta_{\text {opt }}$ & $\mathrm{N}$ & $\beta_{\text {opt }}$ \\
\hline $\mathbf{1}$ & 78 & $\mathbf{5 6}$ & 85 & $\mathbf{9 7}$ & 94 & $\mathbf{1 4 3}$ & 100 & $\mathbf{2 3 7}$ & 96 & $\mathbf{2 7 1}$ & 89 \\
$\mathbf{1 2}$ & 79 & $\mathbf{6 1}$ & 86 & $\mathbf{1 0 2}$ & 95 & $\mathbf{2 0 2}$ & 101 & $\mathbf{2 4 5}$ & 95 & $\mathbf{2 8 0}$ & 88 \\
$\mathbf{2 4}$ & 80 & $\mathbf{6 6}$ & 88 & $\mathbf{1 0 8}$ & 96 & $\mathbf{2 1 4}$ & 99 & $\mathbf{2 5 1}$ & 94 & $\mathbf{2 8 2}$ & 87 \\
$\mathbf{3 3}$ & 81 & $\mathbf{7 2}$ & 89 & $\mathbf{1 1 6}$ & 97 & $\mathbf{2 2 3}$ & 98 & $\mathbf{2 5 5}$ & 93 & $\mathbf{2 9 9}$ & 84 \\
$\mathbf{4 6}$ & 83 & $\mathbf{7 7}$ & 90 & $\mathbf{1 2 6}$ & 99 & $\mathbf{2 2 9}$ & 97 & $\mathbf{2 5 8}$ & 92 & $\mathbf{3 1 0}$ & 82 \\
$\mathbf{5 1}$ & 84 & $\mathbf{8 4}$ & 91 & $\mathbf{1 3 0}$ & 99 & $\mathbf{2 3 6}$ & 96 & $\mathbf{2 6 3}$ & 91 & $\mathbf{3 6 1}$ & $\mathbf{7 8}$ \\
\hline
\end{tabular}

TABLE. 2 OPTIMAL TILT ANGLES OF THE BOOSTER MIRROR B-2 AND THEIR CORRESPONDING DAYS FOR $34^{0}$ LATTUDE LOCATION

\begin{tabular}{|c|c|c|c|c|c|c|c|c|c|c|c|}
\hline $\mathrm{N}$ & $\theta_{\mathrm{opt}}$ & $\mathrm{N}$ & $\theta_{\mathrm{opt}}$ & $\mathrm{N}$ & $\theta_{\mathrm{opt}}$ & $\mathrm{N}$ & $\theta_{\mathrm{opt}}$ & $\mathrm{N}$ & $\theta_{\mathrm{opt}}$ & $\mathrm{N}$ & $\theta_{\mathrm{opt}}$ \\
\hline 1 & 21 & 39 & 26 & 71 & 33 & 113 & 43 & 180 & 49 & 255 & 38 \\
\hline 7 & 21 & 44 & 27 & 79 & 35 & 116 & 43 & 201 & 47 & 263 & 36 \\
\hline 13 & 22 & 50 & 28 & 84 & 36 & 123 & 44 & 211 & 46 & 272 & 34 \\
\hline 19 & 23 & 56 & 29 & 89 & 37 & 129 & 45 & 223 & 44 & 305 & 26 \\
\hline 26 & 24 & 58 & 30 & 103 & 40 & 137 & 47 & 236 & 42 & 319 & 24 \\
\hline 32 & 25 & 65 & 31 & 108 & 42 & 159 & 48 & 240 & 41 & 365 & 21 \\
\hline
\end{tabular}

The dimensions of the SBC used for the analysis are given in Table.3. Fig.7 shows the actual dual BM Solar cooker, with it's primary BM facing South is shown in Fig.7.

TABLE. 3 DIMENSION OF THE SBC

\begin{tabular}{cccc}
\hline $\begin{array}{c}\text { Height } \\
(\mathrm{cm})\end{array}$ & $\begin{array}{c}\text { Width } \\
(\mathbf{c m})\end{array}$ & $\begin{array}{c}\text { Length } \\
(\mathbf{c m})\end{array}$ & $\begin{array}{c}\text { Aspect ratio } \\
\text { (length/width) }\end{array}$ \\
\hline 33 & 45 & 120 & 2.66 \\
\hline
\end{tabular}




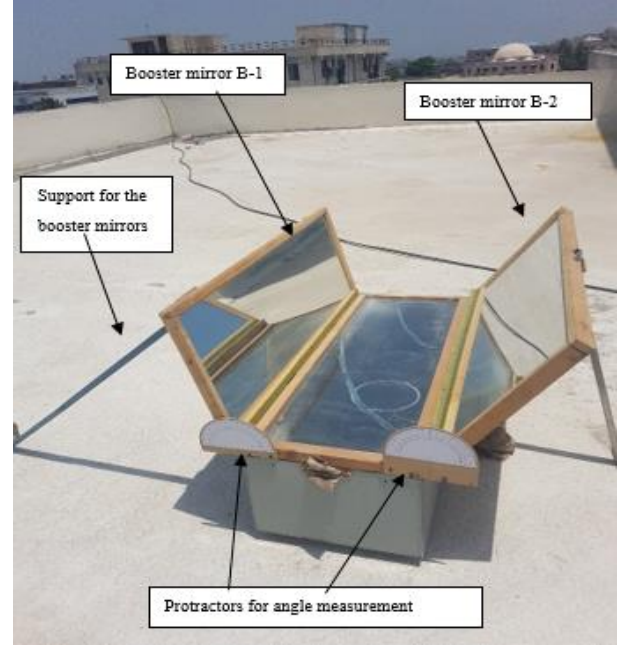

Figure.7 The dual BM solar cooker with the primary BM facing south

For conducting the extensive performance parameters of the dual BM solar cooker, four tests were conducted. The first test was conducted on 7th May, 2019 under unloaded conditions. And the rest of the three tests were conducted on 14th, 20th, and 21 st May respectively under fully loaded conditions. The capacity of the cooker based on the aperture area was $3200 \mathrm{~g}$. The exact same amount of Water was used for standard testing of the cooker. the load was evenly distributed in three containers of the same size. For the unloaded conditions the base temperature is noted until the point when there was no more rise in the base temperature. For the loaded conditions, along with the cooker base temperature, the food vessel's temperature was also noted down. The loaded tests were kept going on until the water inside the vessels reached its boiling point. For all the experiments the ambient temperature and solar irradinace was also measured. The readings were measured after every 5 minutes. The irradiance meter used for measuring the soalr irradiance was METEON 2.0 irradiance meter. The ambient temperature was measured with UNIT-T UT33D Multimeter. the results of the unloaded test are plotted in Fig.8. The data of all the three loaded tests are plotted in Fig.9-Fig.11. since there were three containers used, the cooking vessel's temperature at every instant is the average of the temperature of the three vessels. The solar irradiance measured for all the tests, if plotted against the solar time, will give the results as show in Fig.12

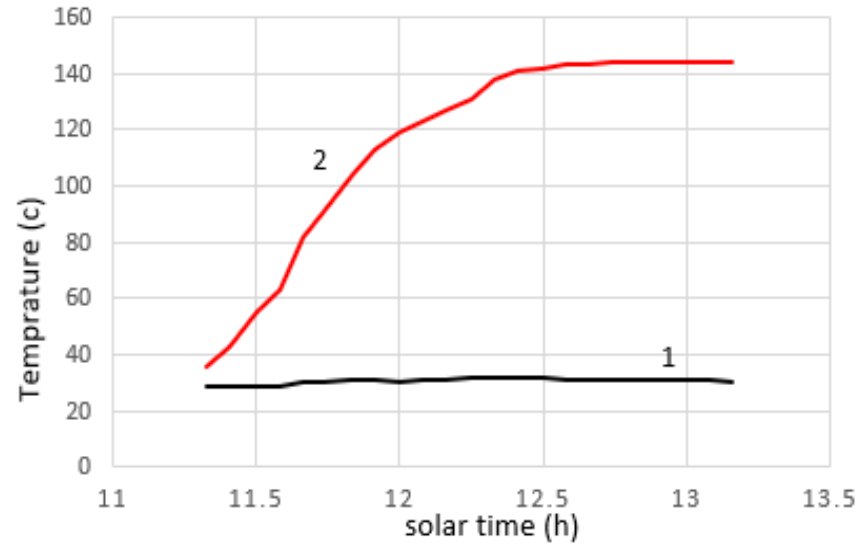

Figure.8 Temperature Vs time Plot for the unloaded conditions with curve 2 showing the cooker base temperature and curve 1 showing the ambient temperature

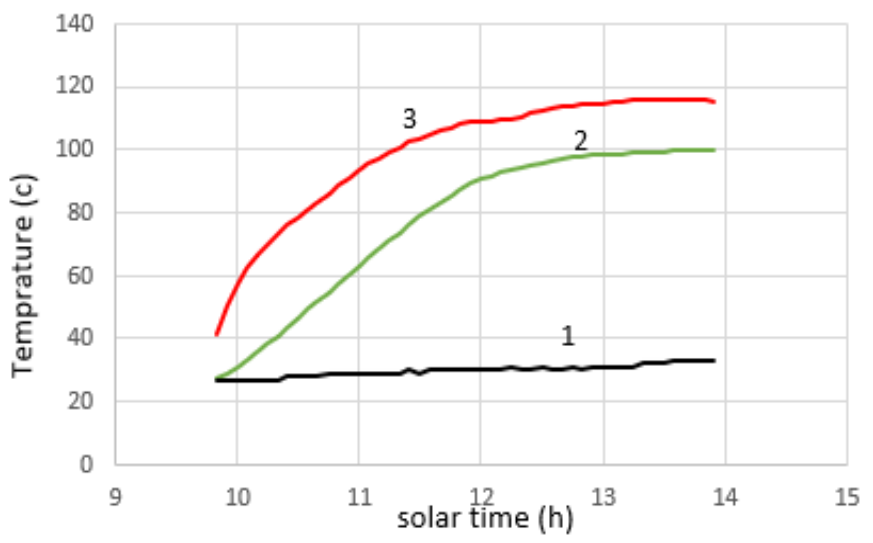

Figure.9 Temperature Vs Solar Time plot for first test under loaded conditions. curve 1 shows ambient temperature, curve 2 shows the average temperature of the water in the containers and curve 3 shows the base temperature

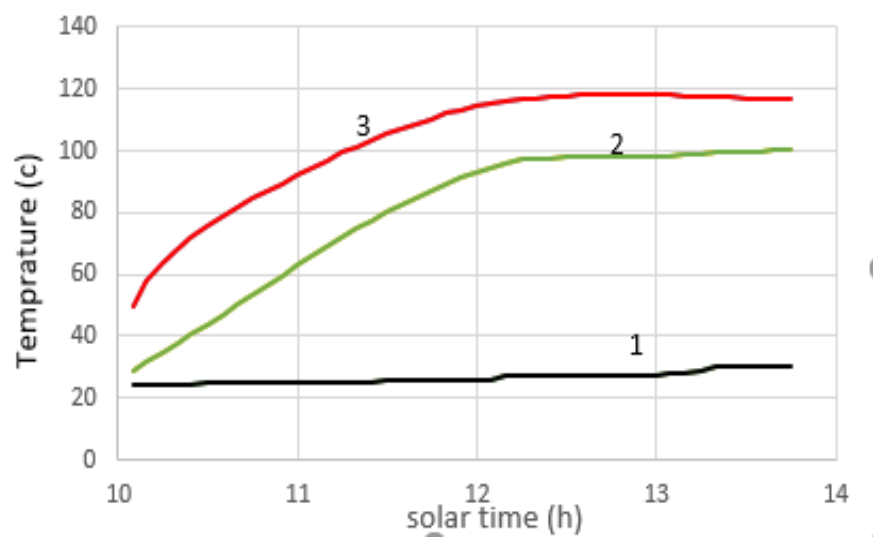

Figure.10 the second test under loaded conditions with curve 1 showing the ambient temperature, curve 2 showing the average temperature of the water in the containers and curve 3 showing the base temperature 


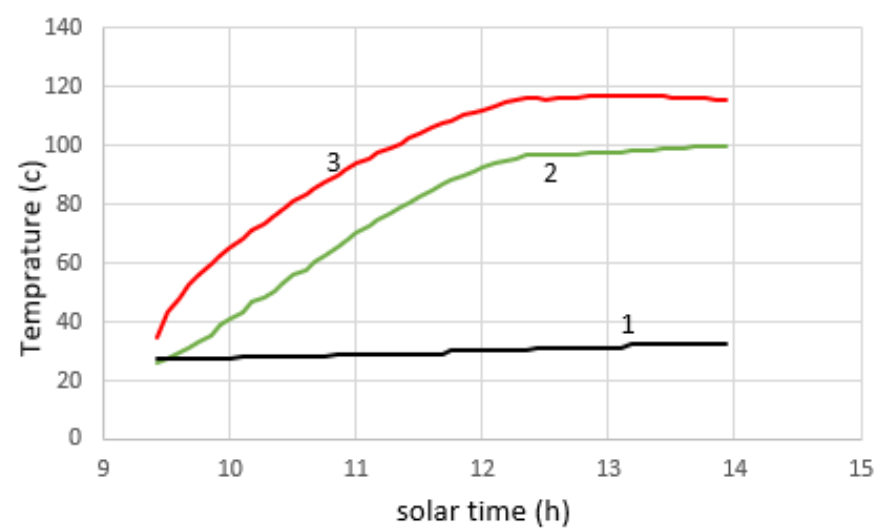

Figure.11 Temperature Vs ST plot for the third test under loaded conditions with curve 1 showing the ambient temperature, curve 2 showing the average temperature of the water in the containers and curve 3 showing the base temperature

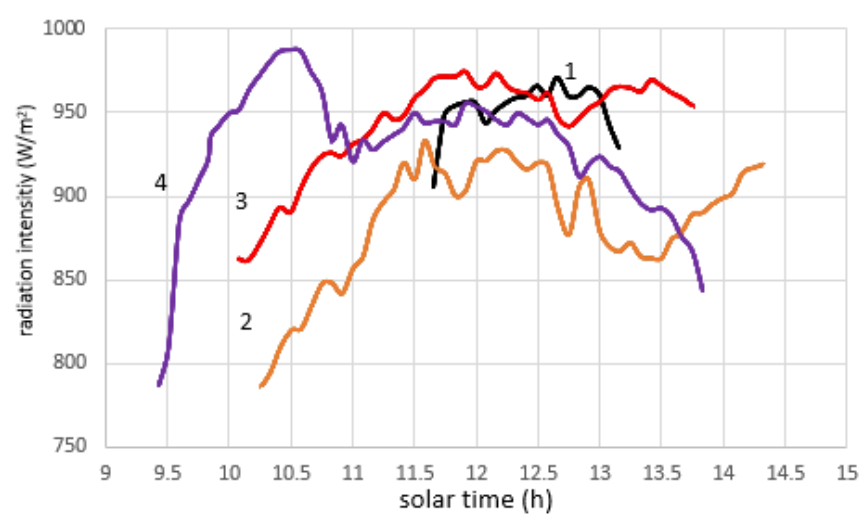

Figure.12 Plot of the solar irradiance Vs Solar time for all the four tests conducted under unloaded and loaded conditions

2. First and Second Figures of Merit $\left(F_{1}\right.$ and $\left.F_{2}\right)$

The first and second FOM are the thermal performance indicators of solar cookers. The first FOM is represented by $F_{1}$ and is the ratio of the optical efficiency to the heat loss factor.The first FOM is evaluated for the unloaded test and is given by

$$
F_{1}=\frac{T_{b}-T_{a m b}}{H_{S}}
$$

$\mathrm{Tb}$; solar cooker base temperature

Tamb ; ambient temperature

Hs ; average Solar insolation $(\mathrm{W} / \mathrm{m} 2)$

The second FOM $F_{2}$ is evaluated for the solar cooker under loaded conditions. For the purpose of finding $F_{2}$ the water is heated sensibly up to $100^{\circ} \mathrm{C}$. The second figure of merit is the measure of heat transferred from the absorbing plate to the water that is being heated inside the solar cooker. $\mathrm{F}_{2}$ is given by

$$
F_{2}=\frac{F_{1}(M C)}{A \cdot t} \ln \frac{\left[1-\frac{\left(T_{w i}-T_{a v}\right)}{F_{1} \cdot H_{a v}}\right]}{\left[1-\frac{\left(T_{w f}-T_{a v}\right)}{F_{1} \cdot H_{a v}}\right]}
$$

MC ; product of mass and specific heat of Water
A ; solar cooker aperture area

$\mathrm{t} \quad$; time taken by the water to boil

$\mathrm{T}_{\mathrm{av}} ;$ average ambient temperature

$\mathrm{T}_{\mathrm{wi}}$; water temperature

$\mathrm{T}_{\mathrm{wf}}$; final water temperature

$\mathrm{H}_{\mathrm{av}}$; average solar insolation

The first FOM $\mathrm{F}_{1}$ is given in Table. 4

TABle. 4 CALCUlation OF THE First Figure OF MERIT

\begin{tabular}{rrrr}
\hline $\mathrm{T}_{\mathrm{b}}\left({ }^{\circ} \mathrm{C}\right)$ & & $\mathrm{H}_{\mathrm{s}}\left(\mathrm{W} / \mathrm{m}^{2}\right)$ & $\mathrm{F}_{1}$ \\
& $\mathrm{~T}_{\mathrm{amb}}\left({ }^{\circ} \mathrm{C}\right)$ & & \\
\hline 144 & 30 & 929 & 0.122 \\
\hline
\end{tabular}

The cooking power of a solar cooker is an indication of the rate at which heat energy is supplied to a specific mass of the food inside the solar cooker. The cooking power is given by $\dot{Q}=\frac{M_{w} C_{w}\left(T_{f}-T_{i}\right)}{t}$
$\mathrm{M}_{\mathrm{w}}$; mass of water
$\mathrm{C}_{\mathrm{w}}$; specific heat of water
$\mathrm{T}_{\mathrm{i}}$; initial temperature of water
$\mathrm{T}_{\mathrm{f}}$; final temperature of water
$\mathrm{t}$; time taken

The cooking Power and $F_{2}$ is calculated in Table.5. Since three loaded experiments are conducted, the value of $F_{2}$ and the cooking power for the solar cooker is the average of the values calculated for all the three experiments.

\section{Exergy Efficiency and Quality factor}

The exergy of a device is the measure of its potential to derive heat from the surrounding [3]. The exergy efficiency is the ratio of the exergy input to the system to the exergy output of the system. The exergy input to the solar cooker is the exergy of solar radiation flux which is given by equation

$$
E_{x i}=I^{\circ} A \Delta t\left[1+\left(\frac{T_{a}}{T_{s}}\right)^{4}\left(\frac{1}{3}\right)-\left(\frac{4}{3}\right)\left(\frac{T_{a}}{T_{s}}\right)\right]
$$

Where $I^{\circ}$ is the instantaneous solar insolation, $T_{a}$ is the ambient temperature, $T_{S}$ is the temperature of the surface of the Sun, and A is the aperture area of the SC. The exergy out is given by

$$
E_{x o}=M C_{w}\left[\left(T_{f}-T_{i}\right)-T_{a} \ln \left(T_{f} / T_{i}\right)\right]
$$

Ta ; ambient temperature

The second term in equation (17) represents the exergy loss from the system. Exergy efficiency is calculated by diving equation (17) by (16) Thus exergy efficiency is given by

$$
\varphi=\frac{\left[\frac{(M C)_{w}\left[\left(T_{w f}-T_{w i}\right)-T_{a} \ln \left(T_{w f} / T_{w i}\right)\right]}{\mathrm{t}}\right]}{I^{\circ} A \Delta t\left[1+\left(\frac{T_{a}}{T_{S}}\right)^{4}\left(\frac{1}{3}\right)-\left(\frac{4}{3}\right)\left(\frac{T_{a}}{T_{S}}\right)\right]}
$$


The exergy input to the system as given by equation(16) is calculated and the result for all the three sets of experiment is plotted in Fig.13. similarly the exergy output calculated for all the three sets of the loaded experiments is plotted in Fig.14. The plots of the exergy efficiency for all the three loaded experiments is given in Fig. 15.

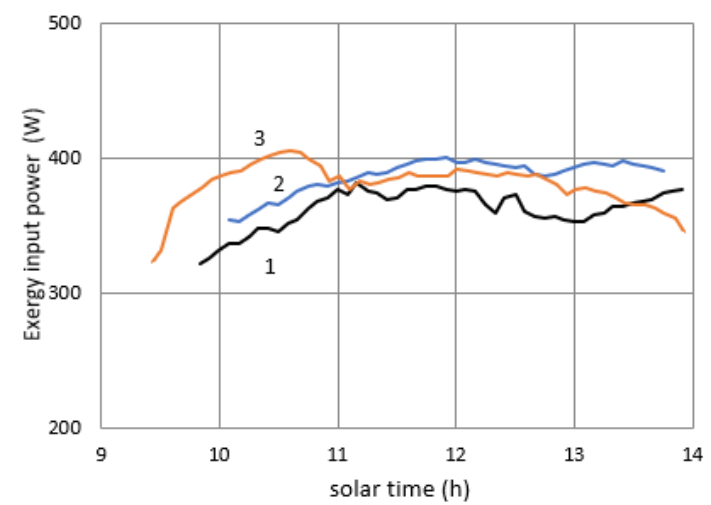

Figure.13 Plot of the Exergy input vs solar time for all the three experiments conducted under loaded conditions. Curves are labeled according to the experiments

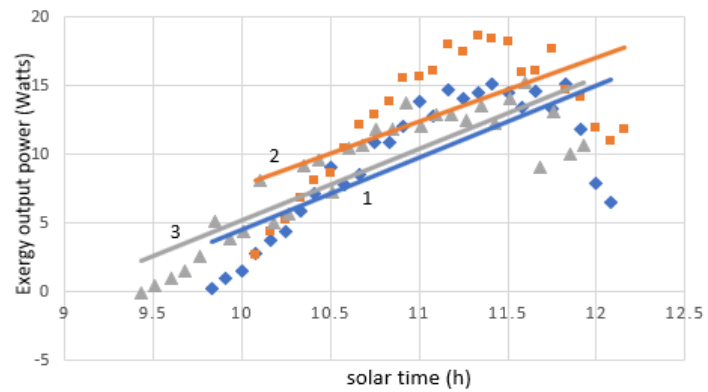

Figure.14 Exergy utput power Vs solar time plot for the three tests conducted under loaded conditions. the trendlines are numbered according to the experiments number

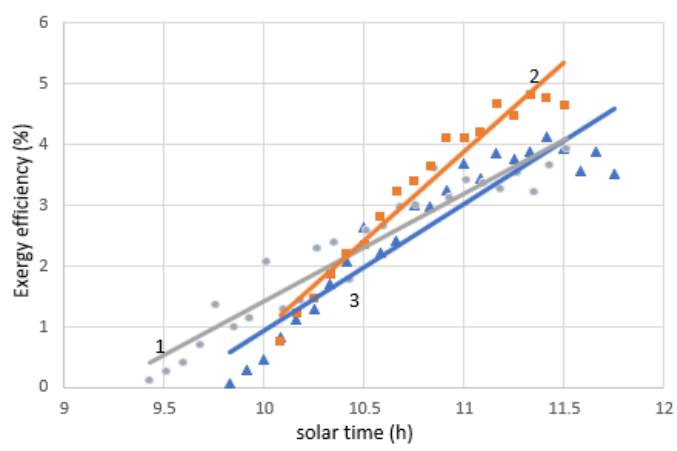

Figure.15 plot of the Exergy efficiency vs solar time. The curves are labelled according to the experimen

TABLE.5 CALCULATIONS OF THE SECOND FiguRE OF MERIT AND COOKING POWER

\begin{tabular}{cccccccccc}
\hline Exp no & $\begin{array}{c}\text { Aperture Area } \\
\left(\mathrm{m}^{2}\right)\end{array}$ & $\begin{array}{c}\mathrm{T}_{\mathrm{wi}} \\
\left({ }^{\circ} \mathrm{C}\right)\end{array}$ & $\begin{array}{c}\mathrm{T}_{\mathrm{wf}} \\
\left({ }^{\circ} \mathrm{C}\right)\end{array}$ & $\begin{array}{c}\mathrm{T}_{\mathrm{av}} \\
\left({ }^{\circ} \mathrm{C}\right)\end{array}$ & $\begin{array}{c}\mathrm{H}_{\mathrm{av}} \\
\left(\mathrm{W} / \mathrm{m}^{2}\right)\end{array}$ & $\begin{array}{c}\text { Duration } \\
(\text { seconds })\end{array}$ & $\begin{array}{c}(\mathrm{M} . \mathrm{C}) \\
(\mathrm{j} / \mathrm{k})\end{array}$ & $\mathrm{F}_{2}$ & $\begin{array}{c}\text { Cooking Power } \\
\mathrm{P}(\mathrm{W})\end{array}$ \\
\hline 1 & 0.44 & 27 & 100 & 29.8 & 884 & 16200 & 13440 & 0.25 & 60.5 \\
2 & 0.44 & 28.4 & 100 & 26.44 & 943 & 13200 & 13440 & 0.278 & 72.9 \\
3 & 0.44 & 25.6 & 100 & 29.5 & 928 & 16200 & 13440 & 0.233 & 61.7 \\
& & & & \multicolumn{7}{c}{ Average } & 0.254 & 65 \\
\hline
\end{tabular}

TABLE.6 CALCULATION OF THE OVERALL HEAT LOSS COEFFICIENT

\begin{tabular}{cccccc}
\hline Exp No & $\begin{array}{c}\text { Length of } \\
\text { cooker } \mathrm{L}(\mathrm{m})\end{array}$ & $\begin{array}{c}\text { Width of the } \\
\text { cooker W(m) }\end{array}$ & $\begin{array}{c}\text { Gross aperture } \\
\text { area } \mathrm{A}(\mathrm{m} 2)\end{array}$ & $\begin{array}{c}\text { Slope of the } \\
\text { Exergy loss curve } \\
(\mathrm{W} / \mathrm{K})\end{array}$ & $\begin{array}{c}\text { Heat loss } \\
\text { coefficient } \\
\text { (W/Km2) }\end{array}$ \\
\hline 1 & 1.2 & 0.45 & 0.54 & 0.416 & 0.832 \\
2 & $/ /$ & $/ /$ & $/ /$ & 0.648 & 1.2 \\
3 & $/ /$ & $/ /$ & $/ /$ & 0.2082 & 0.385 \\
& & & & Average & 0.78 \\
\hline
\end{tabular}


TABLE.7 CALCULATIONS OF THE QUALITY FACTOR FOR ALL THE THREE EXPERIMENTS CONDUCTED UNDER LOADED CONDITIONS

\begin{tabular}{ccccc}
\hline $\begin{array}{c}\text { Experiment } \\
\text { No }\end{array}$ & $\begin{array}{c}\text { Peak Exergy gain EX } \\
(\mathrm{W})\end{array}$ & $\begin{array}{c}\text { Temperature difference } \\
\Delta \boldsymbol{T}\end{array}$ & $\begin{array}{c}\text { Exergy loss EX }(\mathrm{W}) \text { at } \\
\Delta \boldsymbol{T}\end{array}$ & $\begin{array}{c}\text { Quality } \\
\text { facorEx } / \mathrm{Ex}_{\mathrm{L}}\end{array}$ \\
\hline 1 & 14.17 & & & 0.04 \\
& & 37.05 & 350.3 & \\
2 & 18.22 & 39.901 & 370 & 0.049 \\
3 & 12.654 & 37.109 & 375.9 & 0.033 \\
& & & Average & 0.04 \\
\hline
\end{tabular}

The exergy analysis of the cooker is considered to be a more complete synthesis technique because of the fact that it considers the quality as well as quantity of energy transferred from the solar cooker and vice versa. As proposed by (Kumar et al.) a graph of exergy output and temperature difference is plotted and the data points are fitted to a second order polynomial. The fitting of the data points to a second order polynomial makes it easy to obtain the peak value of exergy which is in a close proximity with the actual value of the peak exergy[4]. The exergy output data is plotted against the temperature difference and the data is fitted to the second order polynomial for all the three loaded experiments. To give a clear view of the plot the results are plotted separately for all the three experiments as shown in Fig.16-Fig.18. From the fitted curves, the temperature difference gap is obtained which is the value of the $\mathrm{x}$-axis (Twater -Tamb) corresponding to the half exergy point of the curve. The exergy output curves are plotted separately for all the three loaded experiments.The exergy loss data (Exi-Exout) is plotted againts the difference of the water and ambient temperature for all the three loaded experiments. The plots are given in Fig.19-Fig.21. The slope of exergy loss curve divided by the gross aperture area gives the overall heat loss coefficient of the solar cooker in (W/K.m2). The overall heat loss coefficient of the cooker is the average of the overall heat loss coefficient for all the three experiments. The heat loss coefficient is calculated in Table.6.

TABLES.8 DATA OF THE ON-FIELD TESTS OF THE SOLAR COOKER

DATE: JUNE $18^{\text {TH }}, 2019$

\begin{tabular}{|c|c|c|c|c|c|c|}
\hline container & food items & $\begin{array}{l}\text { starting } \\
\text { time }\end{array}$ & Irradiance $\left(\mathrm{w} / \mathrm{m}^{2}\right)$ & $\mathrm{T}_{\text {ave }}\left({ }^{\circ} \mathrm{C}\right)$ & $\begin{array}{l}\text { Time } \\
\text { taken }\end{array}$ & comments \\
\hline 1 & $\begin{array}{c}350 \mathrm{~g} \text { split green gram }+700 \mathrm{~g} \\
\text { water }\end{array}$ & & & & 2.1 hours & Properly cooked \\
\hline 2 & $\begin{array}{l}\text { 350g Split Red Lentil+700g } \\
\text { water }\end{array}$ & $10: 10 \mathrm{am}$ & 848 & 30 & 2.1 hours & $\begin{array}{l}\text { Slightly } \\
\text { overcooked }\end{array}$ \\
\hline 3 & $\begin{array}{c}\text { 350g split black gram } \\
+700 \mathrm{~g} \text { water }\end{array}$ & & & & 2.1 hours & Properly Cooked \\
\hline
\end{tabular}

DATE: JUNE $24^{\mathrm{TH}}, \mathbf{2 0 1 9}$

\begin{tabular}{llllll}
\hline \multirow{2}{*}{ container } & food items & $\begin{array}{l}\text { starting } \\
\text { time }\end{array}$ & Irradiance $\left(\mathrm{w} / \mathrm{m}^{2}\right)$ & $\mathrm{T}_{\text {ave }}\left({ }^{\circ} \mathrm{C}\right)$ & $\begin{array}{l}\text { Time } \\
\text { taken }\end{array}$ \\
\hline
\end{tabular}

$1350 \mathrm{~g}$ chickpeas $+700 \mathrm{~g}$ water

2.5 hours Properly cooked 


\section{DATE: JUNE 26 ${ }^{\text {TH }}, 2019$}

\begin{tabular}{ccccccc}
\hline container & food items & $\begin{array}{l}\text { starting } \\
\text { time }\end{array}$ & Irradiance $\left(\mathrm{w} / \mathrm{m}^{2}\right)$ & $\mathrm{T}_{\text {ave }}\left({ }^{\circ} \mathrm{C}\right)$ & $\begin{array}{c}\text { Time } \\
\text { taken }\end{array}$ & comments \\
\hline 1 & $\begin{array}{c}1 \text { kg chicken }+250 \mathrm{~g} \text { yogurt } \\
\text { paste }\end{array}$ & & & 3 hours & Properly cooked \\
2 & $350 \mathrm{~g}$ veal+600g water & $10: 20 \mathrm{am}$ & 821 & 31 & & \\
& & & & 3 hours & Properly oooked
\end{tabular}

$3 \quad 300 \mathrm{~g}$ rice $+200 \mathrm{~g}$ Pea beans

$$
+700 \mathrm{~g} \text { water }
$$

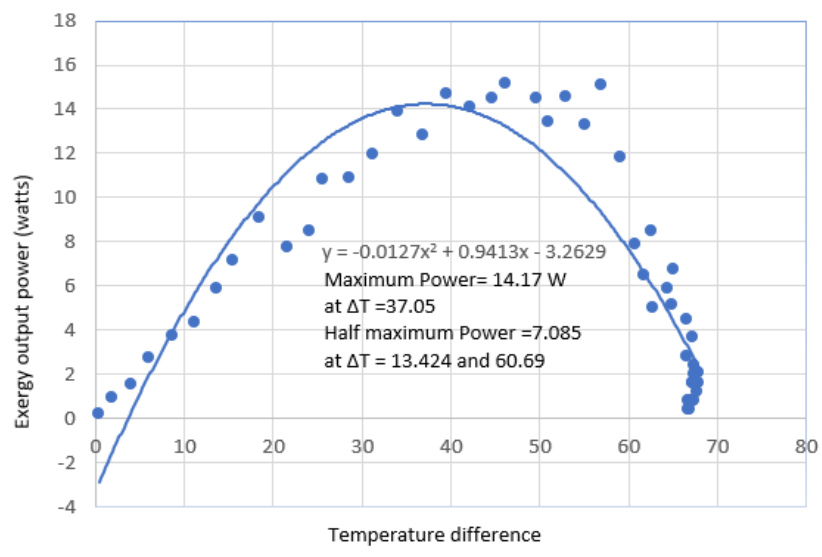

Figure.16 Second order polynomial fit to the Exergy output data for experiment No1 conducted on 14th May

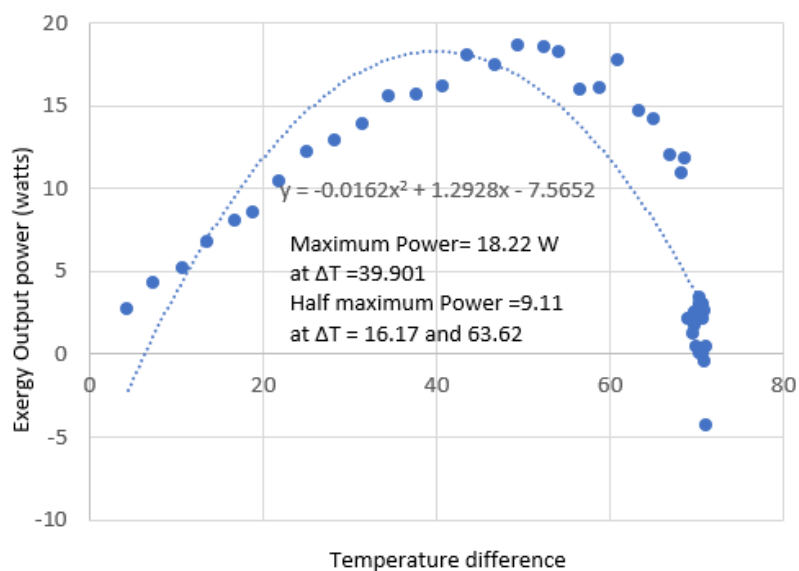

Figure.17 second degree polynomial fit to the Exergy output data for experiment No2 conducted on May $20^{\text {th }}$ 


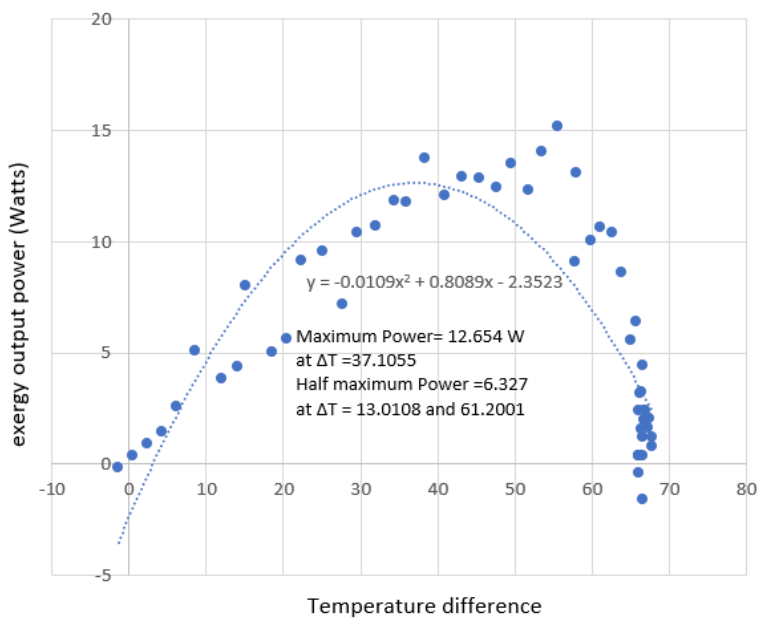

Figure.18 second degree polynomial fit to the Exergy output data for the 3rd experiment conducted on May 21st

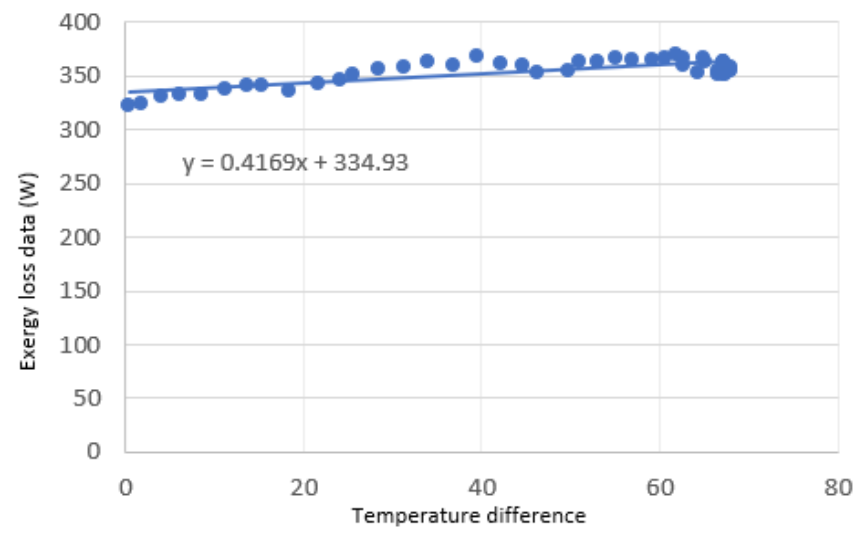

Figure.19 Least square fit to the Exergy loss data for experiment \# 1

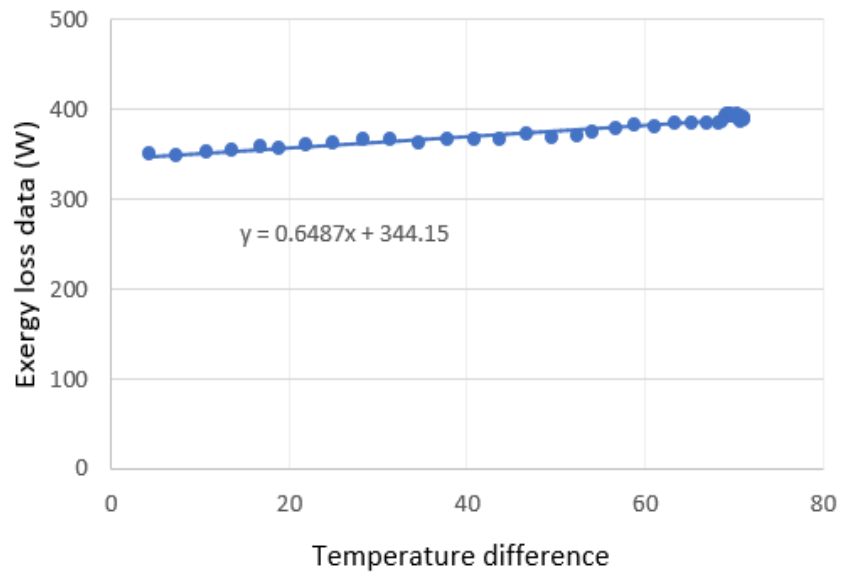

Figure.16: Least square fit to the Exergy loss data for experiment \# 2

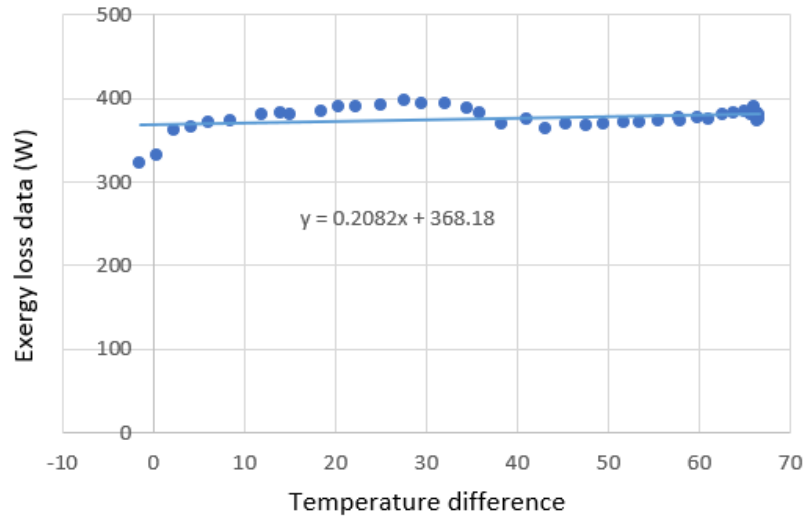

Fig.I-17: Least square fit to the Exergy loss data for experiment \# 3

The Quality facor of the cooker is obtained by dividing the peak exergy value at that specific difference of temperature.The average Quality factor for all the three experiments is shown in Table.7.

\section{On-field testing of the solar cooker}

The cooker was also used for cooking different types of food items. During cooking, the full load of the food items was kept $3200 \mathrm{gm}$. Three containers were used to cook three different dishes in the cooker in one go. The start and end times of the cooking were noted down. The data of the on-field testing of the cooker is given in Tables.8-11.

\section{CONCLUSIONS}

The performance parameters of the dual BM BSC evaluated under tracking free conditions are satisfactory and suggest that the angular optimization technique is an excellent replacement for the labor involved in adjusting the solar cooker after every 15-30 minutes. The maximum time required to cook a dish is 3 hours, which implies that the same cooker can be used for cooking twice a day, making it possible to cook $6.4 \mathrm{~kg}$ of six different dishes in one day with no need for continuous attention thus making the cooking activity easy and less time consuming.Purohit and Purohit suggested that the value of $F_{1}$ should not be less than 0.11 [4]. The value of $F_{1}$ calculated for the box type dual BM SC is in the range of the optimal values for $F_{1}$ and the cooker is a "Grade-A SBC" based on its calculated value of $F_{1}$. The value of $F_{2}$ is found to be 0.254 . The overall heat loss co-efficient is the average of the heat loss co-efficient for all the three experiments conducted under fully loaded conditions. The overall heat loss co-efficient for the cooker is $0.78 \mathrm{~W} / \mathrm{K} . \mathrm{m} 2$. The quality factor is the average of the quality factor for all the three loaded experiments which is found to be 0.04. The peak exergy power of the cooker is found to be 15.01 watts. All the values of the performance parameters are in a proximity with the suggested values of these performance indicators. It is concluded that under the tracking free conditions the performance of the dual BM BSC with the aspect ratio of 2.66 and optimal tilt angles become optimized and it becomes a viable option for the household water-based cooking. 


\section{REFERENCES}

[1] Miller, K., Tangley, L., 1991. Trees of Life: Saving Tropical Forests and Their Biological Wealth. Beacon Press, Boston

[2] Farooqui, Suhail Zaki. "Angular Optimization of Dual BM SCs Tracking Free Experiments with Three Different Aspect Ratios.” SE, vol. 114, Apr. 2015, pp. 337-348.

[3] Kumar, Naveen, et al. "An Exergy Based Unified Test Protocol for SCs of Different Geometries.” RE, vol. 44, Aug. 2012, pp. 457-462, 10.1016/j.renene.2012.01.085. Accessed 27 July 2019

[4] Purohit, I., and P. Purohit. "Effect of Instrumentation Error on the First and Seco F1nd Figures of Merit $\left(\mathrm{F}_{1}\right.$ and $\left.\mathrm{F}_{2}\right)$ of a Box-Type SC.” International Journal of Ambient Energy, vol. 29, no. 2, Apr. 2008, pp. 83-92, 10.1080/01430750.2008.9675061. Accessed 6 Aug. 2019 